\title{
Neuroprotective effects of electro-acupuncture in spinal cord injury rats via up-regulation of DUSP14
}

\author{
Junfeng Zhang, Yaochi Wu*, Jingjie Xu, Shenghong Zhang, Shisheng Li \\ Department of Acupuncture, Tuina and Traumatology, The Sixth People's Hospital Affiliated to Shanghai Jiaotong University, \\ Shanghai 200233, PR China
}

*For correspondence: Email: yochiwu@126.com; Tel: +86-021-24058523

\begin{abstract}
Purpose: To study the effect and mechanism of action of electro-acupuncture (EA) on nerve regeneration by analyzing the behavior, inflammation and cell death in spinal cord injury (SCI) rat model.

Methods: SCl model was established according to Allen's falling strike method. Electroacupuncture was performed on Jiaji (EX-B2)/Mingmen (GV4) acupoint with a $1 \mathrm{~mA}$ current intermittent wave at a frequency of $2 \mathrm{~Hz}$ for 20 min daily. Interleukin (IL-6) and tumor necrosis factor- $\alpha$ (TNF- $\alpha$ ) levels were measured using ELISA kits. Apoptosis-induced DNA strand breaks were evaluated by TUNEL assay while relative mRNA expression was assessed by quantitative real-time polymerase chain reaction (qRT-PCR). Protein levels were measured by western blot.

Results: Relative mRNA and protein expressions of DUSP14 decreased in SCl rats with time but increased by EA treatment. Further, partial locomotor functional recovery was presented in $\mathrm{SCl}$ rats by EA treatment. Moreover, intraspinal injection of DUSP14 over-expression viral supernatants/EA treatment ameliorated inflammation and apoptosis in SCl rats. Meanwhile, the protein levels of NF-KB p65 (nucleus) and phosphorylated TGF-activated kinase 1 (p-TAK1) increased in SCl rats following EA treatment but were decreased by EA treatment and intraspinal injection of DUSP14 over-expression viral supernatants.

Conclusion: EA acupoint treatment exerts neuroprotective effects in $\mathrm{SCl}$ rats via the reduction of inflammation and apoptosis, and induction of DUSP14.
\end{abstract}

Keywords: Electro-acupuncture, Spinal cord injury, Inflammation, TUNEL index, DUSP14

\begin{abstract}
This is an Open Access article that uses a fund-ing model which does not charge readers or their institutions for access and distributed under the terms of the Creative Commons Attribution License (http://creativecommons.org/licenses/by/4.0) and the Budapest Open Access Initiative (http://www.budapestopenaccessinitiative.org/read), which permit unrestricted use, distribution, and reproduction in any medium, provided the original work is properly credited.
\end{abstract}

Tropical Journal of Pharmaceutical Research is indexed by Science Citation Index (SciSearch), Scopus, International Pharmaceutical Abstract, Chemical Abstracts, Embase, Index Copernicus, EBSCO, African Index Medicus, JournalSeek, Journal Citation Reports/Science Edition, Directory of Open Access Journals (DOAJ), African Journal Online, Bioline International, Open-J-Gate and Pharmacy Abstracts

\section{INTRODUCTION}

Spinal cord injury $(\mathrm{SCl})$ is devastating to humans and affects millions of people around the world [1]. The common causes include recreational and sports accidents $(9 \%)$, violence $(13.5 \%)$, falls $(>22 \%)$ and traffic accidents (38\%). The degree of injury in $\mathrm{SCl}$ patients is depends on the precise location and extent as well as the spinal level of the injury[4].Besides the direct consequences of failed sensory, motor and autonomic nervous system function, later problems including chronic pain, muscle wasting, pressure sores and urinary infections would aggravate the injury in SCl patients [5]. 
Initial spinal cord injury induces a series of complex molecular events called 'secondary injury'[6], including free radical-induced apoptosis, inflammation, phospholipase A2 activation, glutamate excitotoxicity, and induction of intrinsic and extrinsic apoptotic pathways. Nuclear factor kappa B (NF-kB) is one of the major pro-inflammatory transcription factors and plays a critical role in inflammation activation[7]. Moreover, excessive cytokines, neurons apoptosis and glia apoptosis are closely related to the secondary injury [8]. Dual specific phosphatase-14 (DUSP14, also known as MKP6) dephosphorylates MAPK family members p38 MAPK, JNK MAPK and ERK MAPK in vitro[9]. Down regulation of DUSP14 elevates hypoxia/reoxygenation-induced activation of NF$\mathrm{KB}$ and MAPKs signaling, and further aggravates the apoptosis and cardiac dysfunction [10].

Electroacupuncture (EA) is a modified traditional Chinese medicine approach and it could improve sensory and motor function in spinal cord transection[12]. Moreover, electroacupuncture has been widely used in the therapy of peripheral nerve injury for a long time in China [14, 15], but the molecular mechanism remains enigmatic. Therefore, the objective of this study was to explore the effect of EA on nerve regeneration via analyzing the behavior, cell death and inflammation in spinal cord injury rat model.

\section{EXPERIMENTAL}

\section{Animals}

Six week-old male Sprague-Dawley rats (170 $210 \mathrm{~g}$ ) were obtained from Shanghai Lab Animal =Research Center (Shanghai, China) and kept in cages $12 \mathrm{~h}$ light/dark cycle, $23-25^{\circ} \mathrm{C}$ ) with food and water ad libitum. This study was approved by the Animal Care and Use Committee of The Sixth People's Hospital Affiliated to Shanghai Jiaotong University (approval no. 2017-0014) and in accordance with the Guidelines for the Care and Use of Laboratory Animals [17].

\section{Spinal cord injury (SCI) model}

Rats were anesthetized by intraperitoneal injection of sodium pentobarbital ( $40 \mathrm{mg} / \mathrm{kg}$ ), and then fixed in the prone position. A longitudinal incision was sectioned in the middle skin in the rat back after shaved. Then, the vertebral laminae from $T_{9}$ to $T_{11}$ were resected. The $S C I$ model was established according to Allen's falling strike method [18]. The skin and muscles were closed in layers after the injury. Rats in negative control group underwent the same operation except the strike-injury. Manual emptying of bladder was performed 3 times daily until intrinsic function was recovered.

\section{EA treatment}

In the EA treatment group, acupuncture needles (0.25 mm × $13.00 \mathrm{~mm}$, Suzhou Medical Appliance Factory, Suzhou, China) were inserted into the Jiaji (EX-B2) / Mingmen (GV4) acupoints at 3 days after operation. A low frequency electronic pulse therapeutic apparatus (Model G6805-2, Shanghai Medical Electronic Apparatus, Shanghai, China) was connected. The acupoints were stimulated by a $1 \mathrm{~mA}$ current intermittent wave at the frequency of $2 \mathrm{~Hz}$ for 20 min daily. Muscles at the acupoints were characterized by shaking slightly during EA execution. Stimulating at the non-acupoint on the right forelimb was served as electrical stimulation control.

\section{Intraspinal injection of DUSP14 over- expression viral supernatant}

DUSP14 (NM_001270836.1) over-expression lentivirus vectors were constructed by JRDun Biotech (Shanghai, China). Viral supernatants were diluted in rat serum to the required concentration and intraspinal injection into the injury side at $6 \mathrm{~h}$ after $\mathrm{SCl}$ operation.

\section{Experiment design and sample collection}

This study was divided into 3 parts. In the $1^{\text {st }}$ part, a total of 21 SD rats were used (3 normal rats, 3 negative control rats and $15 \mathrm{SCl}$ rats). Three rats in $\mathrm{SCl}$ group were sacrificed at 0,6 , 12,24 and $72 \mathrm{~h}$ after operation respectively. Rats in normal control group and negative control were sacrificed at $72 \mathrm{~h}$ after operation. The injured / normal spinal cord tissue sample was collected. The mRNA expression and protein level of DUSP14 at each time point were measured.

In the $2^{\text {nd }}$ part, 36 SD rats were divided into 6 groups (6 rats per group): negative control group, $\mathrm{SCl}$ group, EA Jiaji (EX-B2) acupoint treatment group, EA Mingmen (GV4) acupoint treatment group, EA Jiaji (EX-B2) + Mingmen(GV4) acupoints treatment group, and EA non-acupoint treatment group. The EA treatment was performed at $6 \mathrm{~h}$ after operation. Combined Behavioral Score (CBS) protocol[19]was employed to analyze the behavior of rats at $24 \mathrm{~h}$ after operation. Then the rats were sacrificed and the spinal cord tissue sample was collected. The mRNA expression and protein level of DUSP14 were tested at the end.

Trop J Pharm Res, September 2019; 18(9): 1832 
In the $3^{\text {rd }}$ part, $30 \mathrm{SD}$ rats were divided into 5 groups (6 rats per group): negative control group, $\mathrm{SCl}$ group, EA Jiaji (EX-B2) + Mingmen (GV4) acupoints treatment group, DUSP14 overexpression viral supernatants intraspinal injection group and empty plasmid control group. The EA treatment and intraspinal injection were performed at $6 \mathrm{~h}$ after operation. Rats were sacrificed at $24 \mathrm{~h}$ after operation and the spinal cord tissue sample and regeneration fluid were collected. The contents of TNF- $\alpha$ and IL-6 were tested using ELISA method. Cell apoptosis of spinal cord tissues were tested by TUNEL assay. The protein levels of DUSP14, NF-KB, cleaved Caspase-3, cleaved poly ADP-ribose polymerase (PARP), TGF-activated kinase 1 (TAK1) and phosphorylated TAK1 ( $\mathrm{p}$-TAK1) were measured by western blot.

\section{ELISA assay}

The spinal cord regeneration fluid was extracted. The TNF- $\alpha$ and IL- 6 content were measured using the rat TNF- $\alpha$ (ab100785, Abcam, USA) and IL-6 (ab100772, Abcam, USA) ELISA kits according to the instructions.

\section{TUNEL assay}

Apoptosis-induced DNA strand breaks were measured using a TUNEL assay kit (11684817910, Roche, USA) in accordance with a previous report[20]. Spinal cord tissue samples were rapidly fixed in 10\% formaldehyde. After standard operation of dehydration, clearing in xylene, and paraffin embedding, 3 5 $\mu \mathrm{m}$ sections were cut and mounted. Then the samples added with $50 \mu \mathrm{L}$ TUNEL reaction mixture were incubated in dark at $37^{\circ} \mathrm{C}$ for $1 \mathrm{~h}$. Finally, the $3^{\prime}$ ends of DNA are labeled with dUPT (fluorescein conjugated) and show deep brown. Finally, the sample sections were observed using a fluorescence microscope (TE2000U, Nikon, Japan). Moreover, the apoptotic index of each sample was calculated by counting the positive and negative stained cells in fields of vision.

\section{Polymerase chain reaction}

Total RNA of spinal cord tissues was isolated using TRIzol reagent (15596018, Thermo Fisher, USA) and then reverse transcribed into cDNA using the first strand cDNA synthesis kit (K1622, Thermo Fisher, USA). Q-RT PCR was performed on an $\mathrm{ABI} 7500$ system (ABI-7500, USA) using SYBR Green qPCR Master Mixes (4385612, Thermo Fisher, USA) with the primers (Table 1). Relative mRNA expression was calculated using the $2^{-\Delta \mathrm{Ct}}$ method normalized to GAPDH.
Table 1: Primers used in real-time fluorogenic PCR assay

\begin{tabular}{|c|c|c|}
\hline $\begin{array}{l}\text { Gene } \\
\text { name }\end{array}$ & Sequence (5'-3') & Description \\
\hline DUSP14 & $\begin{array}{c}\text { ATGGCTCCTCGGATGA } \\
\text { TTTC }\end{array}$ & Forward \\
\hline DUSP14 & $\begin{array}{c}\text { CATTGACGACGCAGGT } \\
\text { GATG }\end{array}$ & Reverse \\
\hline GAPDH & $\begin{array}{c}\text { GGAGTCTACTGGCGTC } \\
\text { TTCAC }\end{array}$ & Forward \\
\hline GAPDH & $\begin{array}{c}\text { ATGAGCCCTTCCACGA } \\
\text { TGC }\end{array}$ & Reverse \\
\hline
\end{tabular}

\section{Western blot}

The total protein was isolated and then determined using a BCA protein assay kit (23227, Thermo Fisher, USA). Besides, nucleoprotein was extracted using a commercial kit (P0027-3, Beyotime Bio, China) according to the instruction. The proteins $(35 \mu \mathrm{g}$ each sample) were separated using $10 \%$ SDS-PAGE. Then target protein was transferred onto a PVDF membrane and blocked using 5\% nonfat milk at $25^{\circ} \mathrm{C}$ for $1 \mathrm{~h}$. Then the membranes were incubated with primary antibodiesDUSP14 (1:2000, NBP1-81046,Novus Bio, USA), Cleaved caspase3 (1:1000, \#9661, CST, USA), Cleaved PARP (1:1000, \#9545, CST, USA), NF-kB p65 (1:1000, Ab16502, Abcam, USA), TAK1 (1:1000, \#5206, CST, USA), p-TAK1 (1:1000, \#9339, CST, USA), Histone H3 (1:2000, \#4499, CST, USA) and GAPDH (1:1000, \#5174, CST, USA) respectively. Followed by incubation with HRP (Horseradish Peroxidase)-conjugated goat antirabbit IgG secondary antibody (1:1000, A0208, Beyotime Bio, China) for $1 \mathrm{~h}$. Finally, protein level was measured using a chemiluminescent imaging system (Tanon 5200, Tanon, China) and normalized to GAPDH/H3.

\section{Statistical analysis}

Data are presented as mean \pm SD. Statistical analysis was processed by SPSS 20.0 software (SPSS, IBM, Chicago, USA). Differences between two samples were analyzed by paired Student's t-test. One-way analysis of variance followed by Dunnett's test was performed for three or more groups. $p<0.05$ was considered as significant.

\section{RESULTS}

\section{Effects of spinal cord injury on DUSP14 expression in rats}

$\mathrm{SCl}$ model was established according to Allen's falling strike method. Then relative mRNA and protein expression of DUSP14 at the injury site 
were tested at $0,6,12,24$ and $72 \mathrm{~h}$ after operation. As shown in Figure 1, relative mRNA and protein expression of DUSP14 were decreased with time in SCI rats.
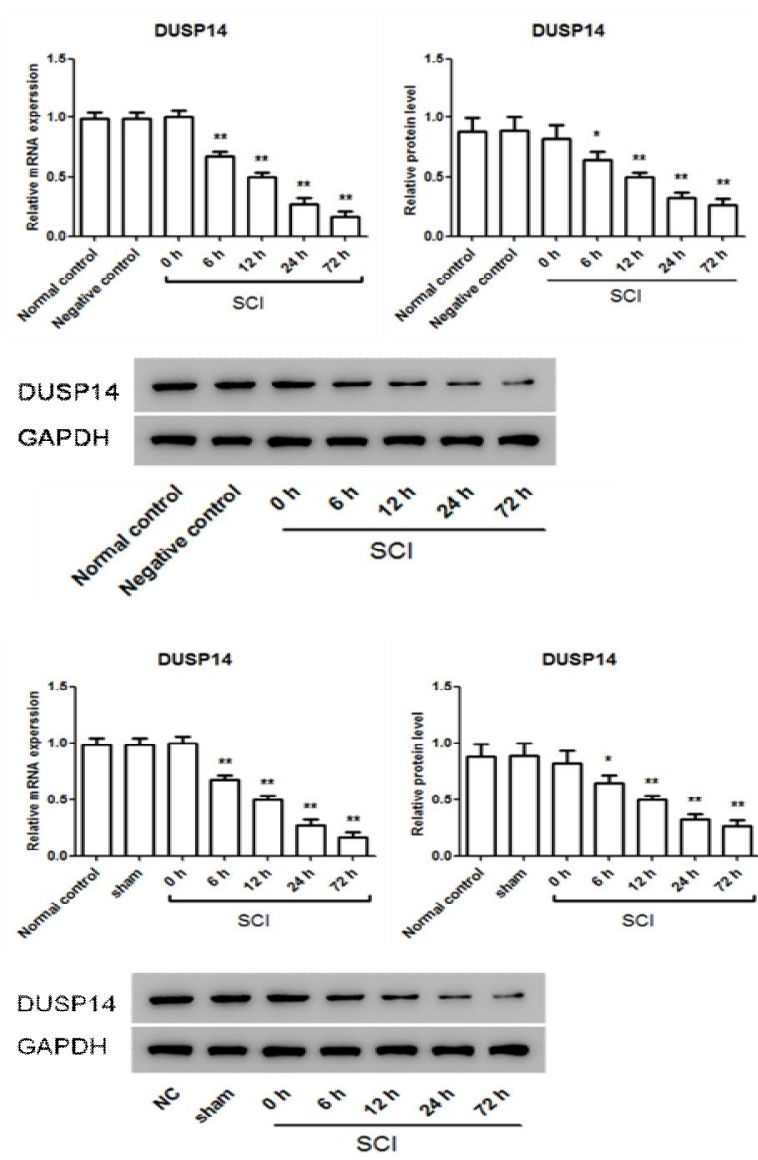

Figure 1: Effects of spinal cord injury on DUSP14 expression in rats. GAPDH was regarded as the loading control; ${ }^{*} p<0.05,{ }^{* *} p<0.01$, compared with negative control group

\section{EA treatment ameliorated the sensory and motor function of $\mathrm{SCl}$ rats and up-regulated the DUSP14 expression}

The Combined Behavioral Score (CBS) protocol [19] was employed to analyze the behavior of rats at $24 \mathrm{~h}$ after operation. Moreover, relative mRNA and protein expressions of DUSP14 were determined by q-RT PCR and western blot respectively. The present results indicated that EA (acupoints) treatment could ameliorate the sensory and motor function of $\mathrm{SCl}$ rats (Figure 2 a) and up-regulated the DUSP14 expression in $\mathrm{SCl}$ rats (Figure $2 \mathrm{~b}$ and $\mathrm{c}$ ). Besides, EA double acupoints treatment showed better treatment effects. Moreover, there was no difference between EA non-acupoints treatment group and $\mathrm{SCl}$ model group (Figure 2).
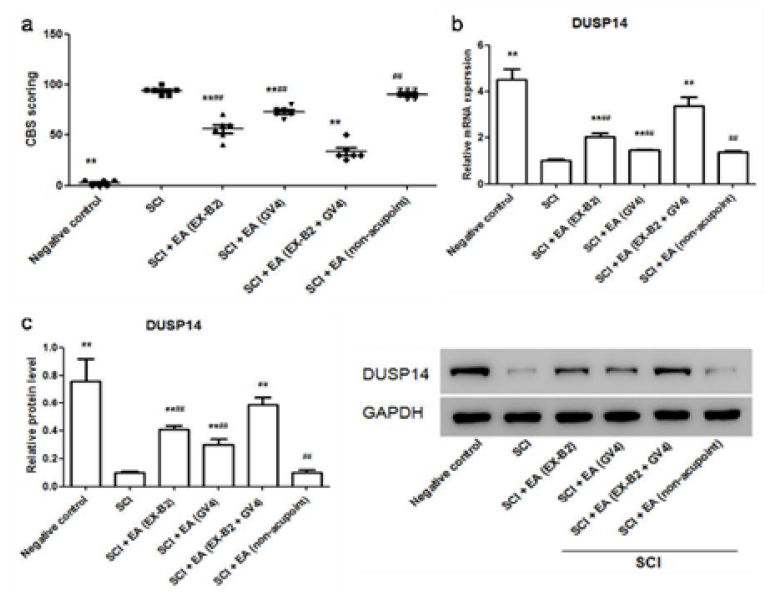

Figure 2: EA treatment ameliorated the behavior of rats and up-regulated the DUSP14 expression in SCl rats. The CBS scoring of $\mathrm{SCl}$ rats was decreased by EA acupoints treatment (a). Relative mRNA and protein expression of DUSP14 were increased by EA acupoints treatment (b and $c) ;{ }^{*} p<0.05,{ }^{* *} p<0.01$, compared with the SCl group; ${ }^{\# \#} p<0.01$ compared with $\mathrm{SCl}+\mathrm{EA}(\mathrm{EX}-\mathrm{B} 2+\mathrm{GV} 4)$ treatment group

EA treatment ameliorated the inflammation and apoptosis at the spinal cord injury site and up-regulated DUSP14

As shown in Figure 3 , the concentration of TNF- $\alpha$ and IL-6 in spinal cord regeneration fluid were increased in $\mathrm{SCl}$ rats but decreased by intraspinal injection of DUSP14 over-expression viral supernatants at the spinal cord injury site (Figure 3 a). Further, SCl-induced increase TNF$\alpha$ and IL-6 were ameliorated by EA (double acupoints) treatment (Figure 3 a). The apoptosisinduced DNA strand breaks were increased in $\mathrm{SCl}$ rats but decreased by EA (double acupoints) and intraspinal injection of DUSP14 overexpression viral supernatants (Figure 3 b). Furthermore, the protein levels of DUSP14 and NF-KB p65 (cytoplasm) decreased in SCl rats but increased by EA (double acupoints) and DUSP14 over-expression (Figure $3 \mathrm{c}$ ). Moreover, the protein levels of cleaved caspase3, cleaved PARP, NF-KB p65 (nucleus) and p-TAK1 showed an opposite trend. Besides, the protein levels of TAK1 showed no change (Figure $3 \mathrm{c}$ ).

\section{DISCUSSION}

$\mathrm{SCl}$ is a serious problem with high prevalence and causing heavy burden to family and social. Initial spinal cord injury induced secondary damages such as inflammation and apoptosis are the major target of most current neuroprotective strategies [6]. The present results indicated that EA acupoints treatment could be an effective treatment method against spinal cord injury. 

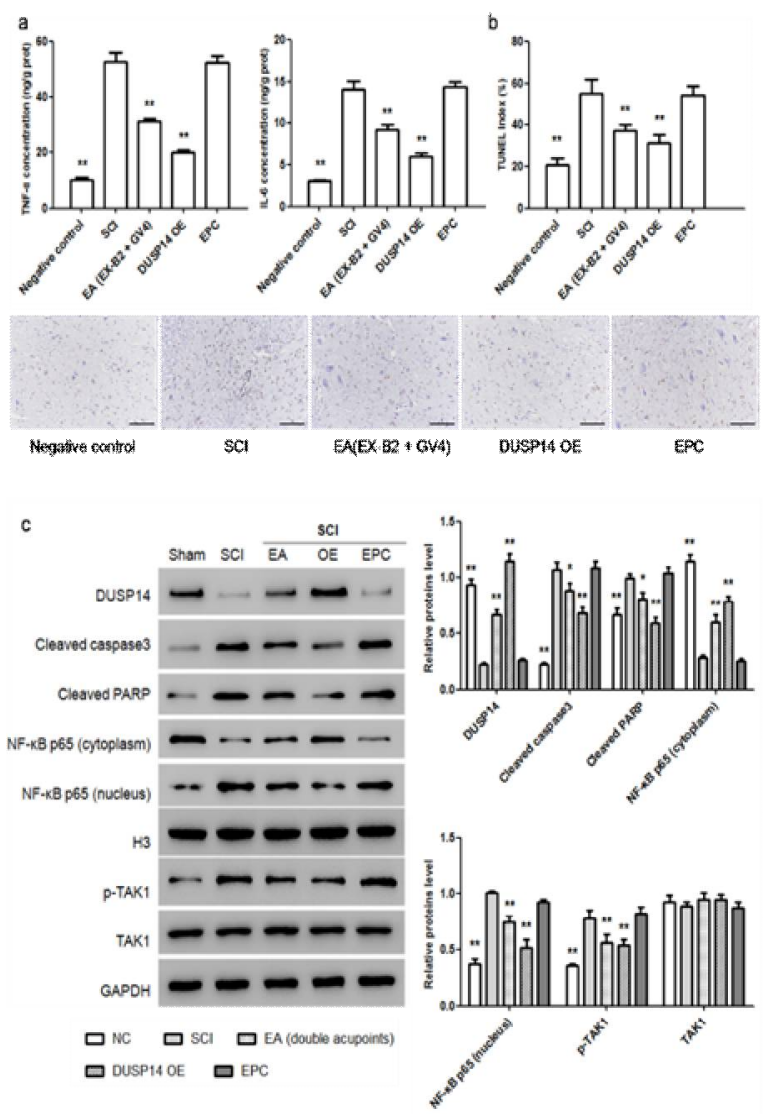

Figure 3: EA treatment ameliorated the inflammation and apoptosis at the spinal cord injury site and upregulated DUSP14. The concentration of TNF- $\alpha$, IL-6 and apoptosis-induced DNA strand breaks (TUNEL index) were increased in $\mathrm{SCl}$ rats but decreased by DUSP14 OE and EA treatment $(a, b)$. Effects of EA in combine with DUSP14 OE on proteins expressions in $\mathrm{SCl}$ rats (c). Scale bar: $10 \mu \mathrm{m} ;{ }^{*} p<0.05,{ }^{* *} p<0.01$, compared with the SCI group/EPC group

Electro-acupuncture (acupoints) treatment ameliorated the behavior of $\mathrm{SCl}$ rats. Moreover, the inflammation and apoptosis induced by $\mathrm{SCl}$ was improved by EA (acupoints) treatment via the up-regulation of DUSP14.

Dual specific phosphatase-14 is a phosphatase and dephosphorylates MAPK family members[9]. It plays a key role in protecting cardiac from hypoxia/reoxygenation injury via suppressing activation of MAPKs and NF-KB signaling [10]. TGF-activated kinase 1 is closely linked with the MAPK and NF-KB signaling. Activated TAK1 can accelerate the MAPK and NF-KB signaling pathways and resveratrol attenuates the inflammation by the inhibition of TAK1 activity $[21,22]$.

A previous study indicated that the posttraumatic inflammation is mediated by the TNF- $\alpha$ -NF-kB cascade [23], and the post-traumatic inflammation was ameliorated by methylprednisolone (MP)- the effective treatment to improve neurological function in patients with acute $\mathrm{SCl}$ [23]. Another report showed that IL6 mediated inflammatory via inducing aquaporin 4 (AQP4) expression in rat spinal cord astrocytic [24]. In the present study, the increased concentrations of TNF- $\alpha$ and IL- 6 as well as protein level of NF-KB p65 (nucleus) and p-TAK1 were decreased by EA (acupoints) treatment and DUSP14 over-expression in $\mathrm{SCl}$ rats. The expression of DUSP14 was up-regulated by EA (acupoints) treatment.

In recent years, the regain of lost nerve function after spinal cord injury has been widely studied [25]. A previous study has also reported that electrical stimulation enhances nerve regeneration with no effects on neuropathic pain [26]. Electro-acupuncture is a modified traditional Chinese medicine approach. It has been reported to induce BDNF,NT-3and NGF expressions in spared L6 dorsal root ganglion in cats subjected to removal of adjacent ganglia [27]. Moreover, EA has been confirmed to improve chronic neuropathic pain after spinal cord injury $[28,29]$.

In this study, the behavior of $\mathrm{SCl}$ rats (CBS scoring) were improved by EA Jiaji (EX-B2) / Mingmen (GV4) acupoints treatment. Moreover, the TUNEL index of $\mathrm{SCl}$ rats was decreased by EA Jiaji (EX-B2) + Mingmen (GV4). The apoptosis-related cleaved caspase 3 and cleaved PARP were decreased by EA Jiaji (EXB2) + Mingmen (GV4) and intraspinal injection of DUSP14 over-expression viral supernatants in $\mathrm{SCI}$ rats.

\section{CONCLUSION}

Electro-acupuncture acupoint treatment affords neuroprotective effects in $\mathrm{SCl}$ rats. It would be an effective treatment on $\mathrm{SCl}$ in patient with minimal side effect.

\section{DECLARATIONS}

\section{Acknowledgement}

This work was funded by Scientific Research Project of Chinese Medicine of Shanghai Health and Family Planning Committee (nos. 2014LP026B and ZJ2016008); Plan of Shanghai Commission of Science and Technology (nos. 16401933900 and 18401902400); Plan of action of Traditional Chinese Medicine of Shanghai for three years (no. ZY[2018-2020]-FWTX- 4020) and Characteristic Diagnosis and Treatment 
Technology Upgrade Project of $\operatorname{TCM}$ ( No. ZY(2018-2020)-ZYJS-01.

\section{Conflict of interest}

No conflict of interest is associated with this work.

\section{Contribution of authors}

We declare that this work was done by the authors named in this article and all liabilities pertaining to claims relating to the content of this article will be borne by the authors. This study was conceived and designed by Yaochi Wu. Data were collected by Jingjie $\mathrm{Xu}$, Shenghong Zhang and Shisheng Li and analysed by Junfeng Zhang and Yaochi Wu. The manuscript was written by Junfeng Zhang and Yaochi Wu and submitted by Yaochi Wu. All authors read and approved the manuscript for publication.

\section{Open Access}

This is an Open Access article that uses a funding model which does not charge readers or their institutions for access and distributed under the terms of the Creative Commons Attribution License (http://creativecommons.org/licenses/by/ 4.0) and the Budapest Open Access Initiative (http://www.budapestopenaccessinitiative.org/rea d), which permit unrestricted use, distribution, and reproduction in any medium, provided the original work is properly credited.

\section{REFERENCES}

1. Friedli L, Rosenzweig ES, Barraud Q, Schubert $M$, Dominici N, Awai L, Nielson JL, Musienko P, NoutLomas $\mathrm{Y}$, Zhong $\mathrm{H}$, et al. Pronounced species divergence in corticospinal tract reorganization and functional recovery after lateralized spinal cord injury favors primates. Sci Translat Med 2015; 7: 302ra134.

2. Gomes-Osman J, Cortes M, Guest J, Pascual-Leone A. A Systematic Review of Experimental Strategies Aimed at Improving Motor Function after Acute and Chronic Spinal Cord Injury. J Neurotrauma 2016; 33: 425-438.

3. Spinal Cord Injury (SCl) Facts and Figures at a Glance. $J$ Spinal Cord Med 2016; 39: 370-371.

4. Kjell J, Olson L. Rat models of spinal cord injury: from pathology to potential therapies. Disease models \& mechanisms 2016; 9: 1125-1137.

5. Abrams GM, Ganguly K. Management of chronic spinal cord dysfunction. Continuum (Minneapolis, Minn) 2015; 21: 188-200.

6. Liu N-K, XU X-M. Neuroprotection and its molecular mechanism following spinal cord injury. Neural Regeneration Res 2012; 7: 2051-2062.
7. Barnes PJ, Karin M. Nuclear Factor-KB - A Pivotal Transcription Factor in Chronic Inflammatory Diseases. New Engl J Med 1997; 336: 1066-1071.

8. Smith JA, Das A, Ray SK, Banik NL. Role of proinflammatory cytokines released from microglia in neurodegenerative diseases. Brain Res Bull 2012; 87: 10-20.

9. Marti F, Krause A, Post NH, Lyddane C, Dupont B, Sadelain M, King PD. Negative-Feedback Regulation of CD28 Costimulation by a Novel Mitogen-Activated Protein Kinase Phosphatase, MKP6. J Immunol 2001; 166: 197.

10. Lin $B$, Xu J, Feng $D-G$, Wang $F$, Wang J-X, Zhao $H$. DUSP14 knockout accelerates cardiac ischemia reperfusion (IR) injury through activating NF-KB and MAPKs signaling pathways modulated by ROS generation. Biochemical and Biophys Res Commun 2018; 501: 24-32.

11. Shah PK, Gerasimenko Y. Multi-site spinal stimulation strategies to enhance locomotion after paralysis. Neural Regener Res 2016; 11: 1926-1927.

12. Hu L-N, Tian J-X, Gao W, Zhu J, Mou F-F, Ye X-C, Liu Y$P$, Lu P-P, Shao S-J, Guo H-D. Electroacupuncture and moxibustion promote regeneration of injured sciatic nerve through Schwann cell proliferation and nerve growth factor secretion. Neural Regener Res 2018; 13: 477-483.

13. Li L, Yan H, Campbell G, Lineaweaver WC, Akdemir O, Zhang F. Implanted Electrodes in Peripheral Nerve Stimulation and Recording: Prospects of Their Application in Electronic Prosthesis Design. 2008; 18: 227-237.

14. Chang IA, Namgung U. Induction of Regenerative Responses of Injured Sciatic Nerve by Pharmacopuncture Therapy in Rats. J Acupunct Meridian Studies 2013; 6: 89-97.

15. Hoang NS, Sar C, Valmier J, Sieso V, Scamps F. Electroacupuncture on functional peripheral nerve regeneration in mice: a behavioural study. BMC Complement Altern Med 2012; 12: 141-141.

16. Laboratory animal - guideline for ethical review of animal welfare. 2018.

17. Vogel HG, Vogel WH, Schölkens BA, Sandow J, Müller $P G$, Vogel WF: Guidelines for the Care and Use of Laboratory Animals. 2002.

18. Black P, Markowitz RS, Damjanov I, Finkelstein $S D$, Kushner H, Gillespie J, Feldman M. Models of spinal cord injury: Part 3. Dynamic load technique. Neurosurgery 1988; 22: 51-60.

19. Gale K, Kerasidis H, Wrathall JR. Spinal cord contusion in the rat: Behavioral analysis of functional neurologic impairment. Exp Neurol 1985; 88: 123-134.

20. Takeda K, Uchiyama K, Kinukawa M, Tagami T, Kaneda $M$, Watanabe S. Evaluation of sperm DNA damage in bulls by TUNEL assay as a parameter of semen quality. J Reprod Dev 2015; 61: 185-190.

21. Li H, Ou G, He Y, Ren L, Yang X, Zeng M. Resveratrol attenuates the MSU crystal-induced inflammatory

Trop J Pharm Res, September 2019; 18(9): 1836 
response through the inhibition of TAK1 activity. Int Immunopharmacol 2019; 67: 62-68.

22. Liu X, Botchway BOA. Resveratrol treatment of spinal cord injury in rat model. 2018.

23. $X u$ J, Fan G, Chen $S$, Wu $Y, X u X M$, Hsu CY. Methylprednisolone inhibition of TNF-alpha expression and NF-kB activation after spinal cord injury in rats. Brain research Molecular brain research 1998; 59: 135142.

24. Sun L, Li M, Ma X, Feng H, Song J, Lv C, He Y. Inhibition of $H M G B 1$ reduces rat spinal cord astrocytic swelling and $A Q P 4$ expression after oxygen-glucose deprivation and reoxygenation via TLR4 and NF-KB signaling in an IL-6-dependent manner. J Neuroinflamm 2017; 14: 231 231.

25. Sharp KG, Dickson AR, Marchenko SA, Yee KM, Emery $P N$, Laidmae I, Uibo R, Sawyer ES, Steward O, Flanagan LA. Salmon fibrin treatment of spinal cord injury promotes functional recovery and density of serotonergic innervation. Exp Neurol 2012; 235: 345356.

26. Su HL, Chiang CY, Lu ZH, Cheng FC, Chen CJ, Sheu $M L$, Sheehan J, Pan HC. Late administration of highfrequency electrical stimulation increases nerve regeneration without aggravating neuropathic pain in a nerve crush injury. BMC Neurosci 2018; 19: 37.

27. Chen J, Qi JG, Zhang W, Zhou X, Meng QS, Zhang WM, Wang $X Y$, Wang $T H$. Electro-acupuncture induced NGF, $B D N F$ and NT-3 expression in spared L6 dorsal root ganglion in cats subjected to removal of adjacent ganglia. Neurosci Res 2007; 59: 399-405.

28. Wang JY, Gao YH, Qiao LN, Zhang JL, Duan-Mu CL, Yan YX, Chen SP, Liu JL. Repeated electroacupuncture treatment attenuated hyperalgesia through suppression of spinal glial activation in chronic neuropathic pain rats. BMC Complement Altern Med 2018; 18: 74.

29. $X u J$, Chen XM, Zheng BJ, Wang $X R$. Electroacupuncture Relieves Nerve Injury-Induced Pain Hypersensitivity via the Inhibition of Spinal P2X7 Receptor-Positive Microglia. Anesth Analg 2016; 122: 882-892.

30. Porter AG, Janicke RU. Emerging roles of caspase-3 in apoptosis. Cell Death Differentiat 1999; 6: 99-104.

31. Boulares $A H$, Yakovlev AG, Ivanova V, Stoica $B A$, Wang $G$, lyer S, Smulson M. Role of poly(ADP-ribose) polymerase (PARP) cleavage in apoptosis. Caspase 3resistant PARP mutant increases rates of apoptosis in transfected cells. The Journal of biological chemistry 1999; 274: 22932-22940. 